\title{
Comparison between Different Extraction Methods for Determination of Primary Aromatic Amines in Food Simulant
}

\author{
Morteza Shahrestani, ${ }^{1,2}$ Mohammad Saber Tehrani $\left(D,{ }^{1,5}\right.$ Shahram Shoeibi, ${ }^{2,3}$ \\ Parviz Aberoomand Azar, ${ }^{1}$ and Syed Waqif Husain ${ }^{1,4}$ \\ ${ }^{1}$ Department of Analytical Chemistry, Faculty of Basic Science, Science and Research Branch, Islamic Azad University, Tehran, Iran \\ ${ }^{2}$ Food and Drug Laboratories Research Center (FDLRC), Iran Food and Drug Administration (IFDA), MOH, Tehran, Iran \\ ${ }^{3}$ Department of Food Chemistry, Food and Drug Laboratories Research Center (FDLRC), Iran Food and Drug Administration \\ (IFDA), MOH, Tehran, Iran \\ ${ }^{4}$ Department of Chemistry, Faculty of Science, Science and Research Branch, Islamic Azad University, Tehran, Iran \\ ${ }^{5}$ Department of Analytical Chemistry, Faculty of Basic Sciences, Azad University, Sciences and Researches Branch, \\ P.O. Box 14515-775, Poonak-Hesarak, Tehran, Iran
}

Correspondence should be addressed to Mohammad Saber Tehrani; drmsabertehrani@yahoo.com

Received 4 December 2017; Revised 8 February 2018; Accepted 27 March 2018; Published 15 May 2018

Academic Editor: Krishna K. Verma

Copyright (c) 2018 Morteza Shahrestani et al. This is an open access article distributed under the Creative Commons Attribution License, which permits unrestricted use, distribution, and reproduction in any medium, provided the original work is properly cited.

\begin{abstract}
The primary aromatic amines (PAAs) are food contaminants which may exist in packaged food. Polyurethane (PU) adhesives which are used in flexible packaging are the main source of PAAs. It is the unreacted diisocyanates which in fact migrate to foodstuff and then hydrolyze to PAAs. These PAAs include toluenediamines (TDAs) and methylenedianilines (MDAs), and the selected PAAs were 2,4-TDA, 2,6-TDA, 4,4'-MDA, 2,4'-MDA, and 2,2' -MDA. PAAs have genotoxic, carcinogenic, and allergenic effects. In this study, extraction methods were applied on a $3 \%$ acetic acid as food simulant which was spiked with the PAAs under study. Extraction methods were liquid-liquid extraction (LLE), dispersive liquid-liquid microextraction (DLLME), and solidphase extraction (SPE) with C18 ec (octadecyl), HR-P (styrene/divinylbenzene), and SCX (strong cationic exchange) cartridges. Extracted samples were detected and analyzed by HPLC-UV. In comparison between methods, recovery rate of SCX cartridge showed the best adsorption, up to $91 \%$ for polar PAAs (TDAs and MDAs). The interested PAAs are polar and relatively soluble in water, so a cartridge with cationic exchange properties has the best absorption and consequently the best recoveries.
\end{abstract}

\section{Introduction}

Primary aromatic amines (PAAs) are food contaminants. Migration of PAAs into food is through colored plastics, printed paper, cooking utensils, and flexible packaging. One of the main sources of PAAs is polyurethane (PU) adhesives which are used extensively in lamination of multilayer films. PU adhesives might contain unreacted aromatic diisocyanates coming from the imperfect polymerization process of polyurethane; after packaging, water present in foods hydrolyzes residual aromatic diisocyanates, thus leading to PAA formation [1].

Toluene diisocyanate (TDI) and methylene diphenyl isocyanate (MDI) are used in the production of PU adhesives.
TDIs are often a mixture $(80: 20)$ of the two isomers: 2,4 -TDI and 2,6-TDI, while MDIs consist of a mixture of higher oligomer homologues, 4,4'-MDI (40-50\%), 2, $4^{\prime}$-MDI (2.5-4.0\%), and $2,2^{\prime}$-MDI $(0.1-0.2 \%)[2]$.

PAAs have genotoxic, carcinogenic, and allergenic effects. Epidemiological studies of the $4,4^{\prime}-\mathrm{MDA}$ indicate a risk of bladder cancer in humans, and the 2,4-TDA and $4,4^{\prime}$-MDA are listed as possible human carcinogens [3].

In the European Union (EU) Regulation (10/2011), plastic material and articles shall not release PAAs in detectable quantity (DL $=0.01 \mathrm{mg} / \mathrm{kg})$ in food or food simulants. Chromatography method is recommended for individual identification and quantification of migrated PAAs [4]. 
The extraction/preconcentration of PAAs is required in order to reach the detection limit, prior to analysis. Sample preparation is commonly done for LLE or SPE method [5]. Each one of these two general approaches has advantages and disadvantages; also there has been a new development in the two methods in order to save time, labor, chemicals, and other materials used. This process has led to the creation of new methods such as solid-phase microextraction (SPME), liquid-phase microextraction (LPME), and dispersive liquidliquid microextraction (DLLME) [6].

DLLME technique has been developed and often used for the determination of organic compound in water samples. DLLME is a very simple and rapid extraction method which is used for preconcentration of organic and inorganic compounds from aqueous samples. This method is based on the fast injection of the appropriate mixture of extraction (high-density solvent) and dispersive solvents (polar) into the aqueous solution to form a cloudy ternary component solvent. Extraction process is being completed with centrifugation step, and the enriched analyte is collected in the shape of droplets in the sediment phase [7-9].

Several methods are provided in the literatures for determination of TDIs and MDIs or TDAs and MDAs in the urine, blood, PU foam, water, and waste water samples. These methods are often used with or without hydrolysis of samples, extraction/preconcentration in case of liquid-liquid extraction (LLE) or solid-phase extraction (SPE), and with or without derivatization for GC or HPLC analysis. The selection of extraction methods depends on the type and condition of the sample [10-14].

In this study, two different methods of liquid-phase extraction (LLE, DLLME) and solid-phase extraction (Chromabond C18 ec, Chromabond HR-P, and SCX) were investigated for the extraction of interested PAAs, which were spiked in a $3 \%$ acetic acid as food simulant [15]. Use of $3 \%$ acetic acid which is accepted by the FDA offers the best condition for simulation and a worst-case scenario for this study, and also it is easy to evaluate $[16,17]$. The selection of aromatic amines was based on the type of diisocyanates used to produce PU adhesives. The polyurethane adhesives are often produced from toluene diisocyanates (2,4-TDI and 2,6-TDI) or methylene diphenyl isocyanate $\left(4,4^{\prime}-\mathrm{MDI}\right)$; thus, the PAAs presented are 2,4-TDA, 2,6-TDA, 4, $4^{\prime}$-MDA, $2,4^{\prime}-\mathrm{MDA}$, and $2,2^{\prime}-\mathrm{MDA}$, and the relative recoveries of the PAAs of interest are determined in the $3 \%$ acetic acid matrix.

\section{Materials and Methods}

2.1. Standards and Reagents. The reagents used in this work were all of analytical grade with no further purification. All the reagents were obtained from Merck KGaA, Darmstadt, Germany.

2,6-Toluenediamine, 2,4-toluenediamine, and 4,4' -methylenedianiline (purity $>98 \%$ ) were obtained from Sigma-Aldrich, and 2,4'-methylenedianiline and 2,2' -methylenedianiline (purity $>95 \%$ ) were from Angene.

2.2. Apparatus and Conditions. HPLC system was an Agilent 1200 , equipped with a quaternary pump (G1311A), a column thermostat (G1316A), a degasser unit (G1322A) an autosampler (G1329), and a diode array detector (G1315D). The HPLC system was controlled, and data were analyzed by a computer equipped with LC software (Agilent Chem Station).

The chromatographic conditions were as follows: HPLC analysis was performed with methanol (solvent A) and an ammonium acetate buffer $10 \mathrm{mM}$ (solvent B) as mobile phase. Separation with solvent programming was accomplished on a Phenomenex C18 column $(250 \times 4.6 \mathrm{~mm}$ i.d., $5 \mu \mathrm{m}$ particle sizes); flow rate was $1 \mathrm{ml} \cdot \mathrm{min}^{-1}$, detection wavelength was $235 \mathrm{~nm}$, and temperature was adjusted to $25^{\circ} \mathrm{C}$. The gradient elution process was performed as follows in order to achieve the optimum separation: solvent A was kept at $15 \%$ and solvent B was kept at $85 \%$ for 2 min, solvent A percentage was increased to $65 \%$ along a linear gradient curve for $24 \mathrm{~min}$, and then, solvent A concentration was again increased from $65 \%$ to $100 \%$ along a linear gradient curve for further $2 \mathrm{~min}$ and kept steady at $100 \%$ for another $2 \mathrm{~min}$ and then was decreased to $15 \%$ in the same manner in $1 \mathrm{~min}$ and continued for a further $2 \mathrm{~min}$, giving the total run time of $30 \mathrm{~min}$.

2.3. Standard Solutions and Sample Solutions. The individual stock solutions of each standard with concentration of $100 \mathrm{mg} \cdot \mathrm{l}^{-1}$ in methanol were prepared. These solutions were kept in the darkness and under refrigeration $\left(4^{\circ} \mathrm{C}\right)$ for up to six months. Mixed intermediate standard solutions in methanol were prepared by dissolving appropriate amounts of each individual solution to yield concentrations of $10 \mathrm{mg} \cdot \mathrm{l}^{-1}$. Calibration solutions in methanol/sodium citrate solution $0.1 \mathrm{M}$ (25/75) were prepared daily in the range of $50-800 \mathrm{ng} \cdot \mathrm{ml}^{-1}$.

The sample solutions were prepared from standard mix solutions $10 \mathrm{mg} \cdot \mathrm{l}^{-1}$ with three concentrations $7.5,15$, and $30 \mathrm{ng} \cdot \mathrm{ml}^{-1}$ in $3 \%$ acetic acid $(w / v)$.

\subsection{Extraction Methods}

2.4.1. Liquid-Liquid Extraction Method. For the extraction of PAAs by solvents, the optimized method was applied [12, 13] and modified as follows: an aliquot sample solution of $8 \mathrm{ml}$ was transferred to a test tube, the $\mathrm{pH}$ was adjusted to above 10 with sodium hydroxide, and the solution was saturated with sodium chloride. The sample was extracted three times with $5 \mathrm{~mL}$ portion of mixed dichloromethane/petroleum benzene $(3: 1)$ and followed by twice with $5 \mathrm{~mL}$ of mixed dichloromethane/methyl tert-butyl ether $(1: 1)$. The organic solvent fractions were combined and evaporated to dryness by a stream of nitrogen gas. Finally, the extract was dissolved in $0.8 \mathrm{~mL}$ of methanol/sodium citrate solution $0.1 \mathrm{M}(25 / 75)$ and filtered through a $0.22 \mu \mathrm{m}$ filter for HPLC analysis.

\subsubsection{Dispersive Liquid-Liquid Microextraction Method.} The method used in DLLME was obtained from Wang et al. [8] and Zhou et al. [9], which was modified by the description given below.

A volume of $5 \mathrm{~mL}$ sample solution was placed in a conical bottom tube, $1 \mathrm{~g}$ sodium chloride was added, and the $\mathrm{pH}$ was adjusted to 12 using a $5 \mathrm{~N} \mathrm{NaOH}$ solution. 
TABLE 1: Linearity of PAAs in 3\% acetic acid.

\begin{tabular}{lccc}
\hline Compounds & Regression equation & $\begin{array}{c}\text { Linear range } \\
\left(\mathrm{mgl}^{-1}\right)\end{array}$ & $\begin{array}{c}\text { Correlation } \\
\text { coefficient } \\
\left(R^{2}\right)\end{array}$ \\
\hline $2,6-$ TDA & $Y=0.438 X-2.152$ & $0.05-0.8$ & 0.9996 \\
$2,4-$ TDA & $Y=0.356 X+2.6455$ & $0.05-0.8$ & 0.9987 \\
$4,4^{\prime}-\mathrm{MDA}$ & $Y=0.5104 X-6.0336$ & $0.05-0.8$ & 0.9998 \\
$2,4^{\prime}-\mathrm{MDA}$ & $Y=0.4868 X-4.2338$ & $0.05-0.8$ & 0.9999 \\
$2,2^{\prime}-\mathrm{MDA}$ & $Y=0.3734 X-2.3448$ & $0.05-0.8$ & 0.9999 \\
\hline
\end{tabular}

TABle 2: The recovery of PAAs in 3\% acetic acid.

\begin{tabular}{|c|c|c|c|c|c|c|c|c|c|}
\hline Compounds & $\begin{array}{c}\text { Amount } \\
\text { spiked }\left(\mu \mathrm{g} \cdot 1^{-1}\right)\end{array}$ & Recovery (\%) & RSD & $\begin{array}{c}\text { Amount } \\
\text { spiked }\left(\mu \mathrm{g} \cdot l^{-1}\right)\end{array}$ & Recovery (\%) & RSD & $\begin{array}{c}\text { Amount } \\
\text { spiked }\left(\mu \mathrm{g} \cdot 1^{-1}\right)\end{array}$ & Recovery (\%) & RSD \\
\hline \multicolumn{10}{|l|}{ First day } \\
\hline 2,6-TDA & 7.5 & 90.26 & 2 & 15 & 93.74 & 1.4 & 30 & 96.46 & 1.3 \\
\hline 2,4-TDA & 7.5 & 74.4 & 3.3 & 15 & 87.77 & 3.3 & 30 & 92.92 & 2.6 \\
\hline $4,4^{\prime}-\mathrm{MDA}$ & 7.5 & 83.94 & 2.6 & 15 & 95.28 & 0.95 & 30 & 96.33 & 0.95 \\
\hline $2,4^{\prime}-\mathrm{MDA}$ & 7.5 & 95 & 1.6 & 15 & 94.76 & 1.4 & 30 & 96.86 & 1.4 \\
\hline $2,2^{\prime}-\mathrm{MDA}$ & 7.5 & 81.58 & 2.69 & 15 & 93.58 & 2.71 & 30 & 94.79 & 1.1 \\
\hline \multicolumn{10}{|l|}{ Second day } \\
\hline 2,6-TDA & 7.5 & 90.77 & 2.6 & 15 & 94.04 & 1.4 & 30 & 96.94 & 1.3 \\
\hline 2,4-TDA & 7.5 & 74.90 & 4.2 & 15 & 91.97 & 4.1 & 30 & 93.9 & 1.1 \\
\hline $4,4^{\prime}-\mathrm{MDA}$ & 7.5 & 89.26 & 2.7 & 15 & 94.53 & 1.3 & 30 & 97.03 & 0.43 \\
\hline $2,4^{\prime}-\mathrm{MDA}$ & 7.5 & 96.76 & 1.8 & 15 & 97.08 & 1.1 & 30 & 97.15 & 0.96 \\
\hline $2,2^{\prime}-\mathrm{MDA}$ & 7.5 & 85.02 & 2.18 & 15 & 93.16 & 2.07 & 30 & 94.93 & 4.6 \\
\hline \multicolumn{10}{|l|}{ Third day } \\
\hline 2,6-TDA & 7.5 & 89.76 & 2.4 & 15 & 94.90 & 1.5 & 30 & 95.80 & 1.5 \\
\hline 2,4-TDA & 7.5 & 77.9 & 4.8 & 15 & 91.21 & 2.2 & 30 & 92.9 & 1.8 \\
\hline $4,4^{\prime}-\mathrm{MDA}$ & 7.5 & 88.13 & 0.94 & 15 & 94.79 & 2.5 & 30 & 96.29 & 0.4 \\
\hline $2,4^{\prime}-\mathrm{MDA}$ & 7.5 & 94.94 & 2.17 & 15 & 97.17 & 2.2 & 30 & 98.05 & 1.1 \\
\hline $2,2^{\prime}-\mathrm{MDA}$ & 7.5 & 85.38 & 3.37 & 15 & 94.82 & 4.6 & 30 & 95.44 & 0.61 \\
\hline
\end{tabular}

A mixture of $500 \mu \mathrm{L}$ acetonitrile and $90 \mu \mathrm{L}$ toluene was rapidly injected into the sample using a syringe, and a cloudy solution was obtained. The solution thus prepared was then shaken for $2 \mathrm{~min}$ and was then centrifuged at $6000 \mathrm{rpm}$ for $5 \mathrm{~min}$. The dispersed fine droplets of toluene were sedimented at the bottom of the test tube. The upper layer was removed, and the residual phase was blown to almost dryness with lowpressure nitrogen gas. Finally, the extract was dissolved in $0.5 \mathrm{~mL}$ of methanol/sodium citrate solution $0.1 \mathrm{M}(25 / 75)$ and filtered through a $0.22 \mu \mathrm{m}$ filter for HPLC analysis.

2.4.3. SPE Chromabond ${ }^{\circledR}$ C18 ec. SPE cartridges were conditioned based on the method explained by Oostdyk et al. [5] as the procedure with $5 \mathrm{ml}$ methanol and $5 \mathrm{ml}$ distillated water. Then, $50 \mathrm{ml}$ sample solution was adjusted to $\mathrm{pH} 10$ with $10 \mathrm{M}$ sodium hydroxide solution and was passed slowly through the cartridges. The cartridges were eluted three times with $1 \mathrm{ml}$ of ethyl acetate. Eluents were evaporated in a stream of nitrogen. The remaining residue was dissolved in $5 \mathrm{~mL}$ of methanol/sodium citrate solution $0.1 \mathrm{M}(25 / 75)$ and collected into a $5 \mathrm{ml}$ graduated tube. The solutions were filtered through a $0.22 \mu \mathrm{m}$ filter for HPLC analysis.

2.4.4. SPE Chromabond HR-P. SPE cartridges were conditioned as advised by Macherey-Nagel Company [11], with
$2 \times 5 \mathrm{ml}$ methanol, $2 \times 5 \mathrm{ml}$ acetonitrile, and $2 \times 5 \mathrm{ml} 10^{-5} \mathrm{M}$ sodium hydroxide solution. Then, $50 \mathrm{ml}$ sample solution was adjusted to $\mathrm{pH} 9$ with $10 \mathrm{M}$ sodium hydroxide solution and was passed slowly through the cartridges. The cartridges were eluted by $3 \times 1.5 \mathrm{ml}$ methanol/acetonitrile $(1: 1)$. Eluents were evaporated in a stream of nitrogen. The remaining residue was dissolved in $5 \mathrm{~mL}$ of methanol/sodium citrate solution $0.1 \mathrm{M}(25 / 75)$ and collected into a $5 \mathrm{ml}$ graduated tube. The solutions were filtered through a $0.22 \mu \mathrm{m}$ filter for HPLC analysis.

2.4.5. SPE SCX. Aznar et al. [16] applied SCX cartridges for PAAs, and the method was modified as below: cartridges were conditioned with $2 \times 3 \mathrm{ml}$ methanol and $2 \times 3 \mathrm{ml} 3 \%$ acetic acid $(w / v)$. Then, $50 \mathrm{ml}$ sample solution was passed slowly through the cartridges. The cartridges were eluted with $5 \times 1 \mathrm{ml}$ methanol/sodium citrate solution $0.1 \mathrm{M}$ $(25 / 75)$ and collected into a $5 \mathrm{ml}$ graduated tube. The solutions were filtered through a $0.22 \mu \mathrm{m}$ filter for HPLC analysis.

\subsection{Method Validation of SPE SCX}

2.5.1. Linearity. Linearity was evaluated for mix of five PAAs with concentrations of $50,100,200,400$, and $800 \mu \mathrm{gl}^{-1}$ in 
TABLE 3: Intra- and interday precision of determination of PAAs in 3\% acetic acid.

\begin{tabular}{lccc}
\hline Compounds & Amount spiked $\left(\mu \mathrm{gl}^{-1}\right)$ & Precision (intraday) RSD & Precision (interday) RSD \\
\hline \multirow{3}{*}{2,6 -TDA } & 75 & 0.115 & 0.146 \\
& 150 & 0.115 & 0.278 \\
& 300 & 0.2 & 0.239 \\
$2,4-$ TDA & 75 & 0.115 & 0.188 \\
& 150 & 0.173 & 0.161 \\
\hline & 300 & 0.152 & 0.215 \\
$4,4^{\prime}$-MDA & 75 & 0.058 & 0.139 \\
& 150 & 0.152 & 0.273 \\
$2,4^{\prime}-$ MDA & 300 & 0.1 & 0.256 \\
& 75 & 0.115 & 0.115 \\
$2,2^{\prime}$-MDA & 150 & 0.404 & 0.292 \\
& 300 & 0.058 & 0.153 \\
\hline
\end{tabular}

methanol/sodium citrate solution $0.1 \mathrm{M}$ (25/75) with three replications $(n=3)$ (Table 1$)$.

There was a good linearity in the range of $0.05-0.8 \mathrm{mgl}^{-1}$ for all five target compounds.

2.5.2. Accuracy. In order to investigate the recoveries of the method including SPE procedures, blank food simulants (3\% acetic acid) spiked with five PAAs at three different concentrations $7.5,15$, and $30 \mu \mathrm{gl}^{-1}$ were performed with three replications $(n=3)$. The recoveries are presented for the five aromatic amines (Table 2).

These data confirm not only the accuracy of the method, but also the integrity of the SPE procedure.

2.5.3. Precision. Precision calculation was done based on the repeatability criterion in one day (intraday) and in 3 consecutive days (interday).

Intraday precision was evaluated with spiked blank food simulant (3\% acetic acid) at three different concentrations $7.5,15$, and $30 \mu \mathrm{gl}^{-1}$ including SPE procedures. The RSD of intraday was obtained (Table 3 ).

Interday precision was evaluated with spiked blank food simulant (3\% acetic acid) at three different concentrations $7.5,15$, and $30 \mu \mathrm{gl}^{-1}$ including SPE procedures on three different days. The RSD of interday was obtained (Table 3).

2.5.4. Sensitivity. Relative standard deviation (RSD) of the method was performed with spiked blank food simulant (3\% acetic acid) by five PAAs at concentration $7.5 \mu \mathrm{gl}^{-1}$, including the SPE procedure. LOD and LOQ of the method were calculated (Table 4).

\section{Results and Discussion}

The migration of primary aromatic amines (PAAs) from flexible food packaging represents a serious risk to public health as these compounds are potentially carcinogenic substances. The source of PAAs is from the residues of aromatic
TABLE 4: LOD and LOQ of the method of determination of PAAs in $3 \%$ acetic acid.

\begin{tabular}{lccc}
\hline Compounds & $\begin{array}{c}\text { Limit of } \\
\text { detection }\left(\mu \mathrm{gl}^{-1}\right)\end{array}$ & $\begin{array}{c}\text { Limit of } \\
\text { quantitation }\left(\mu \mathrm{gl}^{-1}\right)\end{array}$ & RSD \\
\hline 2,6-TDA & 1.88 & 5.71 & 0.250 \\
2,4-TDA & 1.86 & 5.64 & 0.201 \\
$4,4^{\prime}$-MDA & 1.44 & 4.37 & 0.223 \\
$2,4^{\prime}$-MDA & 1.36 & 4.13 & 0.201 \\
$2,2^{\prime}$-MDA & 2 & 6.08 & 0.227 \\
\hline
\end{tabular}

diisocyanates (2,4-TDI, 2,6-TDI, and 4,4'-MDI) arising from incomplete curing of the main polyurethane (PU) adhesive, and also other aromatic diisocyanates such as $2,4^{\prime}-\mathrm{MDI}$ and $2,2^{\prime}$-MDI are present in adhesive inappropriately.

The five PAAs (2,4-TDA, 2,6-TD, 4, $4^{\prime}$-MDA, 2, $4^{\prime}$-MDA, and $2,2^{\prime}$-MDA) used in this study were selected on the basis of their origin of PU adhesives used in food packaging. Toxicity of PAAs was evaluated and classified into three groups based on their levels of toxicity with 2,4-TDA, 2,6-TDA, and 4, $4^{\prime}$ MDA being in the high toxicity class [18]. According to the EU Regulation (EU 10/2011), detection limit of the released PAAs must be below $10 \mu \mathrm{g} / \mathrm{kg}$ of food or food simulant. The method was developed and designed based on the worst-case scenario for the migration of PAAs from packaging material into a food simulant which in this study was 3\% acetic acid. The aim of the research was to design and select an extraction method, liquid and/or solid phase, of analysis for these PAAs (TDAs and MDAs) with high sensitivity and also to make possible to understand the origin of the PAAs detected. The method was designed for 3\% acetic acid (as food simulant) in purified water, since this simulant was considered the most restrictive, that means it uses the worst-case scenario for the migration of TDAs and MDAs from food packaging. The direct analysis of the simulant by HPLC-UV did not provide enough sensitivity, as the sample amount injected into the system was very low. For this reason, the LLE and SPE experiments were needed prior to the HPLC detection.

TDAs and MDAs have two functional groups $\left(-\mathrm{NH}_{2}\right)$ that are polar and partly soluble in water; as a result, the 


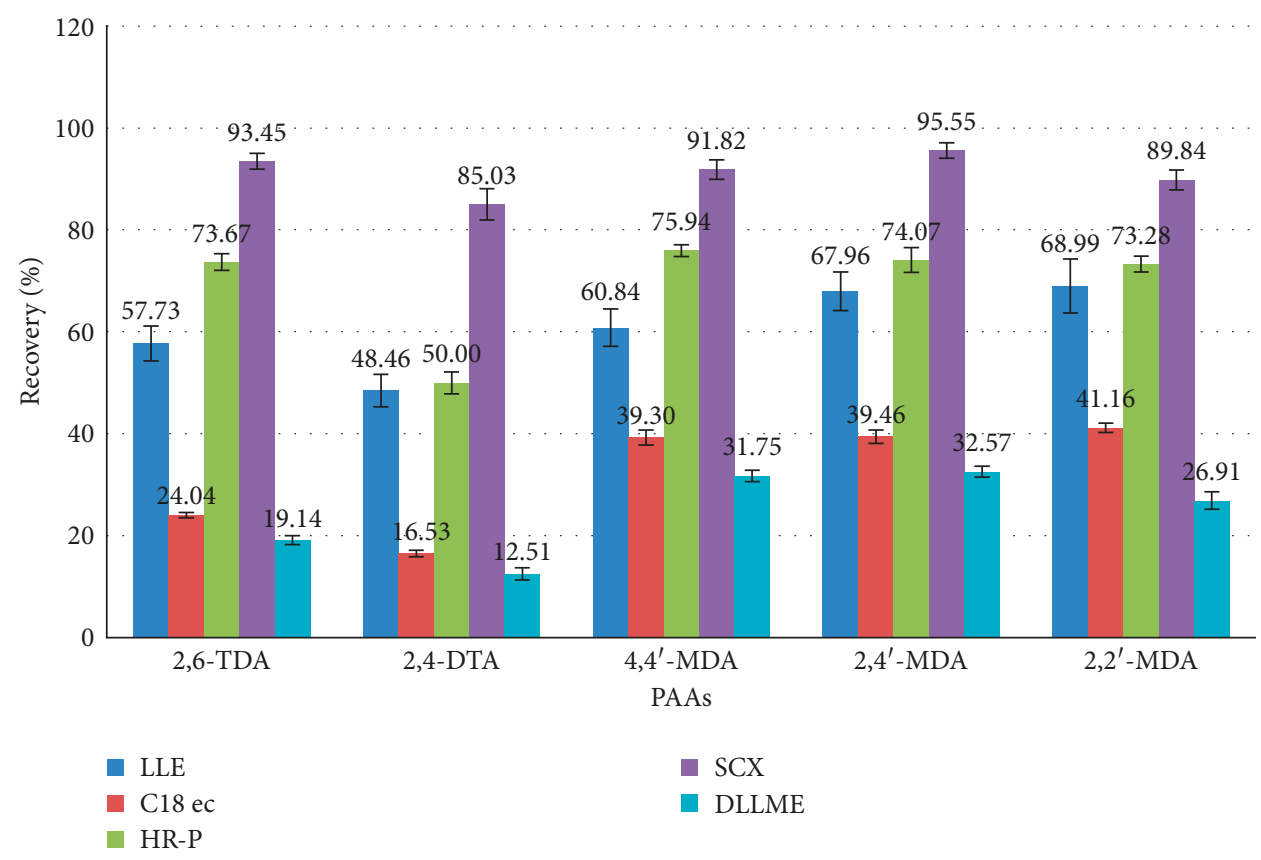

FIgure 1: Compressive of recoveries of extraction methods: LLE, DLLME, SPE C18 ec, SPE HR-P, and SPE SCX for 5 primary aromatic amines.

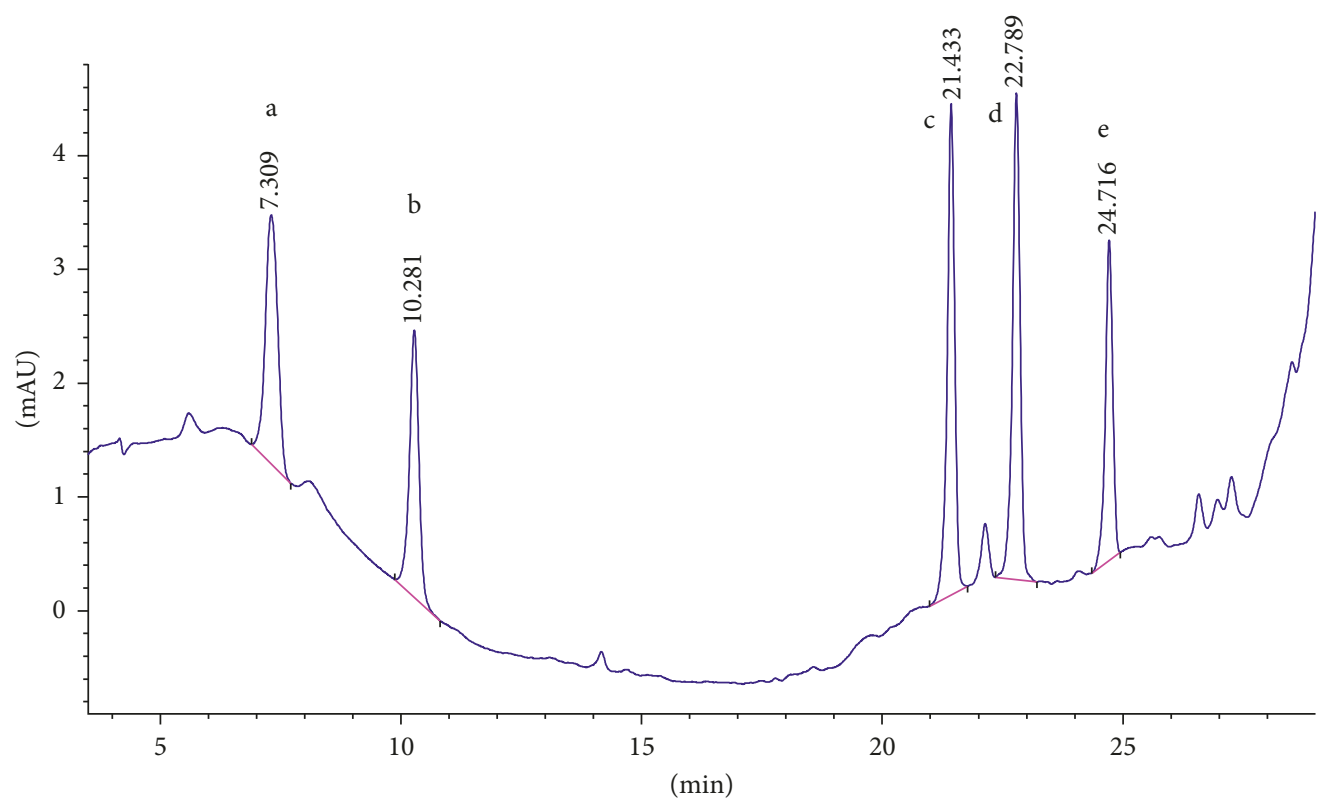

Figure 2: Chromatogram of the standard solution (100 ppb). Peak identified as a: 2,6-TDA, b: 2,4-TDA, c: 4,4'-MDA, d: $2,4^{\prime}{ }^{\prime}$-MDA, and e: $2,2^{\prime}$-MDA.

extraction of these compounds from aqueous solution is difficult [11].

TDAs (single ring) in comparison with MDAs (two rings) have more polarity and are more soluble in water. Therefore, the mean recoveries for the extraction of TDA derivatives (2,4-TDA and 2,6-TDA) should be less than that of MDA derivatives (4, $4^{\prime}$-MDA, $2,4^{\prime}$-MDA, and 2,2' ${ }^{\prime}$-MDA).

In liquid extraction methods, in general data obtained for mean recoveries of extraction for both LLE and DLLME were not very satisfactory. The mean recoveries of LLE is better than those of DLLME, because the number of extraction steps could be increased in the LLE method, while there is just one time dispersion in the DLLME method. The mean recoveries for the extraction of MDAs were greater than that of TDAs in both methods. DLLME were used in extraction of aromatic amines in aqueous matrix with acceptable recoveries $[8,9]$, but in our research, the interested aromatic amines have two functional group $\left(-\mathrm{NH}_{2}\right)$ which are more soluble in aqueous solutions, and consequently, recoveries are lower than LLE and other methods. 


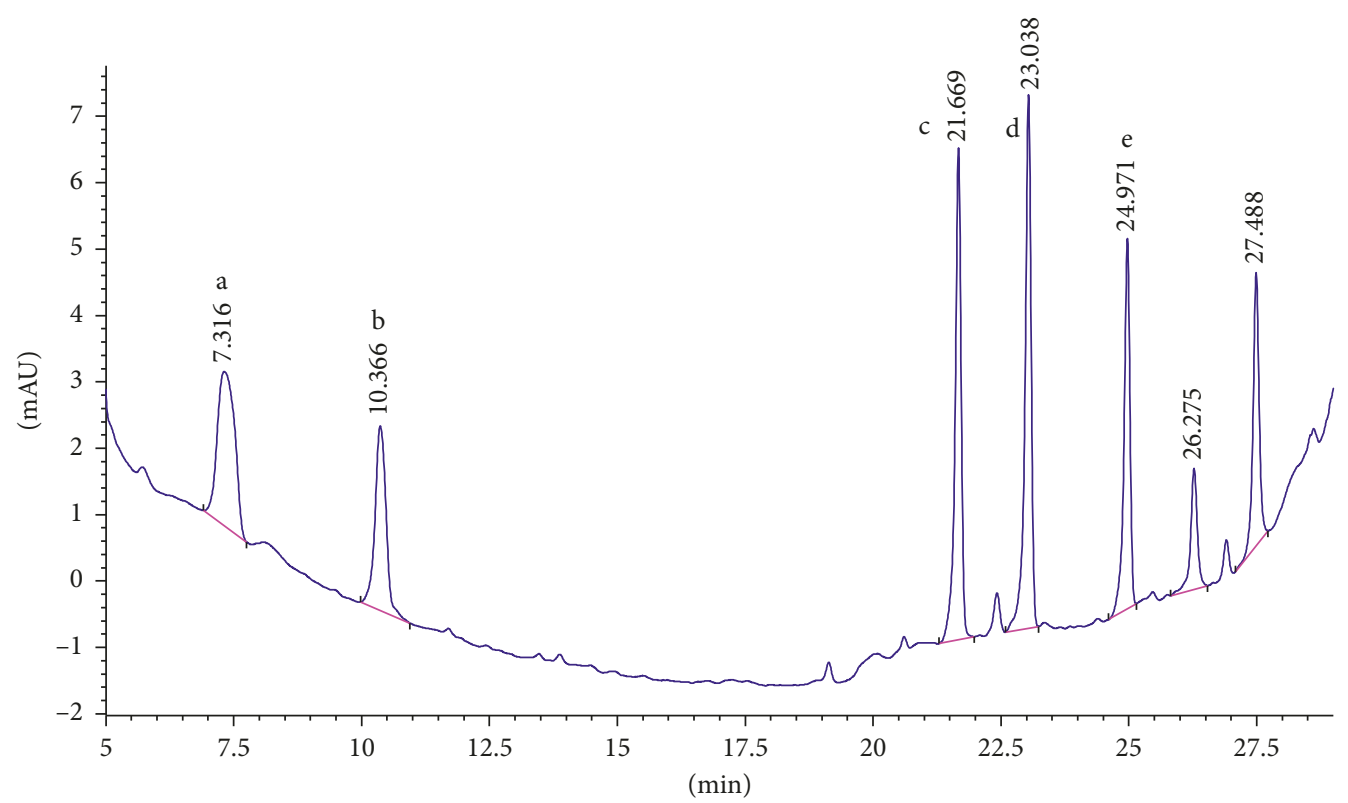

FIgURE 3: Chromatogram of extracted sample spiked (15 ppb) in 3\% acetic acid with SPE SCX. Peak identified as a: 2,6-TDA, b: 2,4-TDA, c: 4,4'-MDA, d: 2,4'-MDA, and e: 2,2'-MDA.

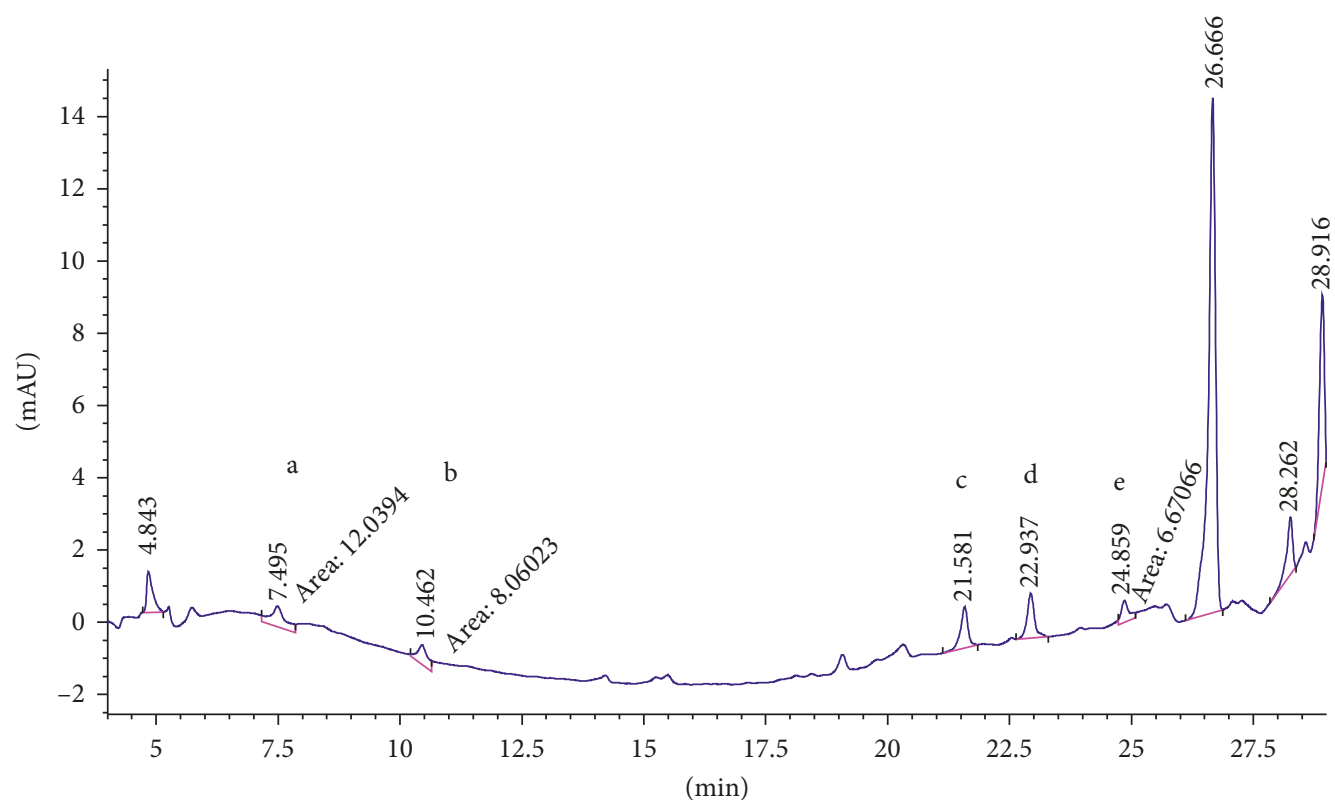

Figure 4: Chromatogram of extracted sample spiked (15 ppb) in 3\% acetic acid with LLDME. Peak identified as a: 2,6-TDA, b: 2,4-TDA, c: $4,4^{\prime}-$ MDA, d: 2,4'-MDA, and e: 2,2'-MDA.

In SPE methods, the mean recoveries of TDAs and MDAs were in the order of SCX > HR-P > C18 ec. Octadecyl sorbents (nonpolar) are not suitable for TDAs and MDAs in the C18 cartridge. In HR-P columns, the cross-linking in SDVB leads to better adsorption than C18 for the polar PAAs. The mean recoveries of the five extraction methods were compared, and the SPE method with SCX cartridge was the best (more than 90\%). The result of all applied methods are compared and shown in Figure 1.
SCX cartridge with the mechanism of action being based on ion exchange could properly adsorb polar PAAs and so has the best mean recovery among the studied cartridges. Figure 2 shows the chromatogram of the standard solution of five PAAs $\left(100 \mathrm{ng} \cdot \mathrm{ml}^{-1}\right)$. The chromatogram of $15 \mathrm{ng} \cdot \mathrm{ml}^{-1}$ spiked food simulant, in which the final concentration of the extracted and preconcentrated solution by SCX cartridge is $150 \mathrm{ng} \cdot \mathrm{ml}^{-1}$, is shown in Figure 3. Also the chromatograms of each method are compared for the performance of the extraction and shown in Figures 4-7. 


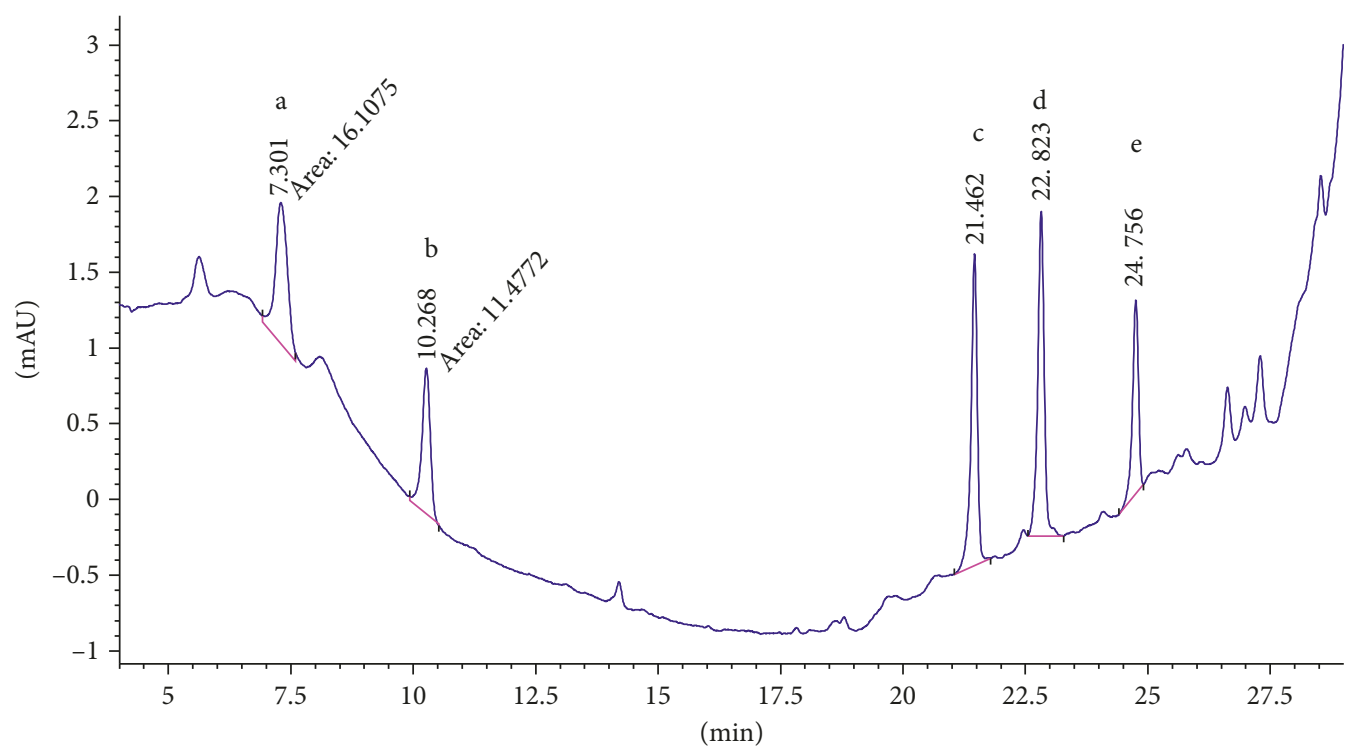

FIgURE 5: Chromatogram of extracted sample spiked (15 ppb) in 3\% acetic acid with SPE C18. Peak identified as a: 2,6-TDA, b: 2,4-TDA, c: $4,4^{\prime}-\mathrm{MDA}, \mathrm{d}: 2,4^{\prime}-\mathrm{MDA}$, and e: $2,2^{\prime}$-MDA.

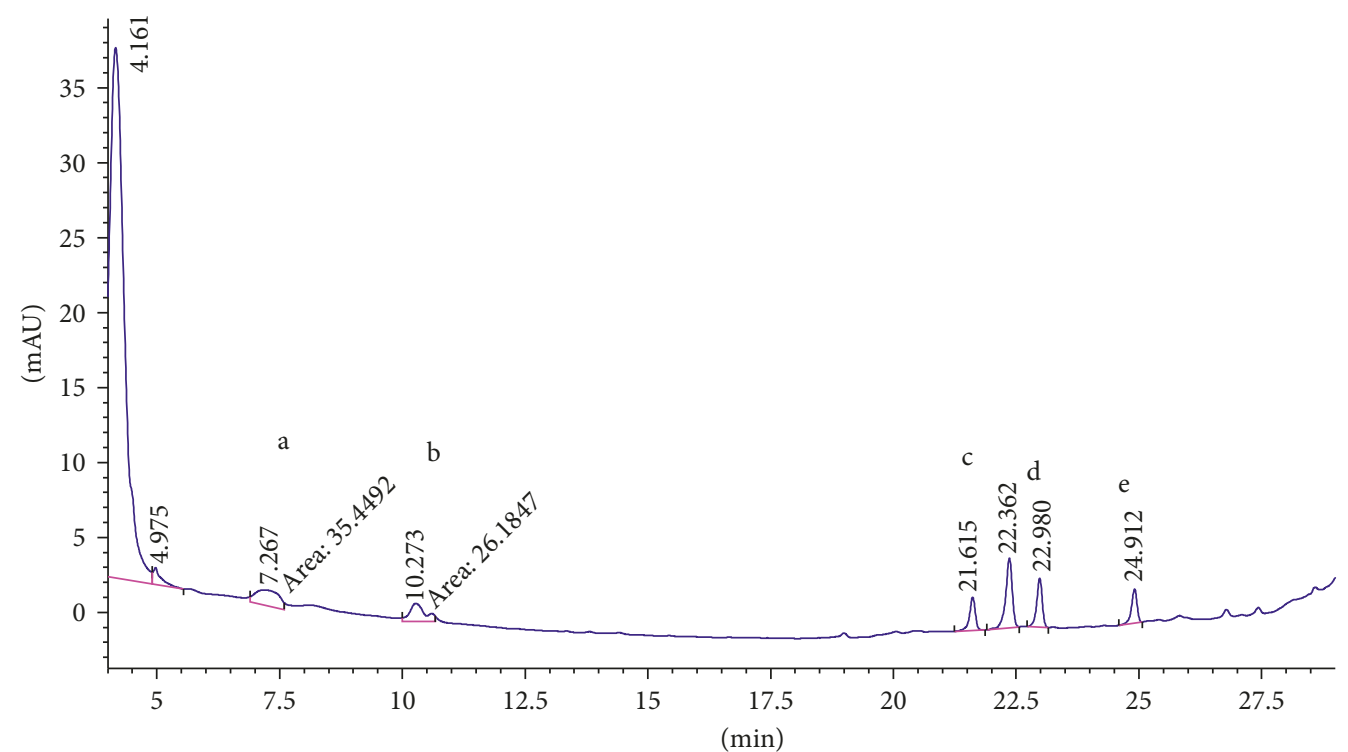

FIgURE 6: Chromatogram of extracted sample spiked (15 ppb) in 3\% acetic acid with SPE HR-P. Peak identified as a: 2,6-TDA, b: 2,4-TDA, c: $4,4^{\prime}-\mathrm{MDA}, \mathrm{d}: 2,4^{\prime}-\mathrm{MDA}$, and e: $2,2^{\prime}-\mathrm{MDA}$.

HPLC method combined with SCX cartridge was validated and developed for the separation and quantitation of five primary aromatic amines in 3\% acetic acid as food simulant. After optimizing all separation parameters, the good separation of five PAAs in food simulant was feasible within $30 \mathrm{~min}$. Additionally, the method was validated for linearity, LOD, precision, and intra- and interday variation.

\section{Conclusions}

It is important to determine and control the migration of contaminants from materials in contact with food into the food. Packaging materials provided this route for migration of contaminants such as PAAs from PU adhesives which are used in laminated multilayer films; some PAAs can migrate to the food. Analysis of PAAs is very valuable in the European regulations, and for this purpose, EU has established regulations for PAAs. Simultaneous extraction and analysis of PAAs (2,4-TDA, 2,6-TDA, 4,4' MDA, 2,4' ${ }^{\prime}$ MDA, and 2,2' MDA) lead to the process of food safety assessment and maintenance, also a means to monitor the use of authorized adhesives and prevention of unauthorized ones being used. Solid-phase extraction SCX is introduced as a suitable method for extraction of polar primary aromatic amines (PAAs) which might have migrated from the laminated multilayer films of packaging materials into 3\% acetic acid as food simulant. 


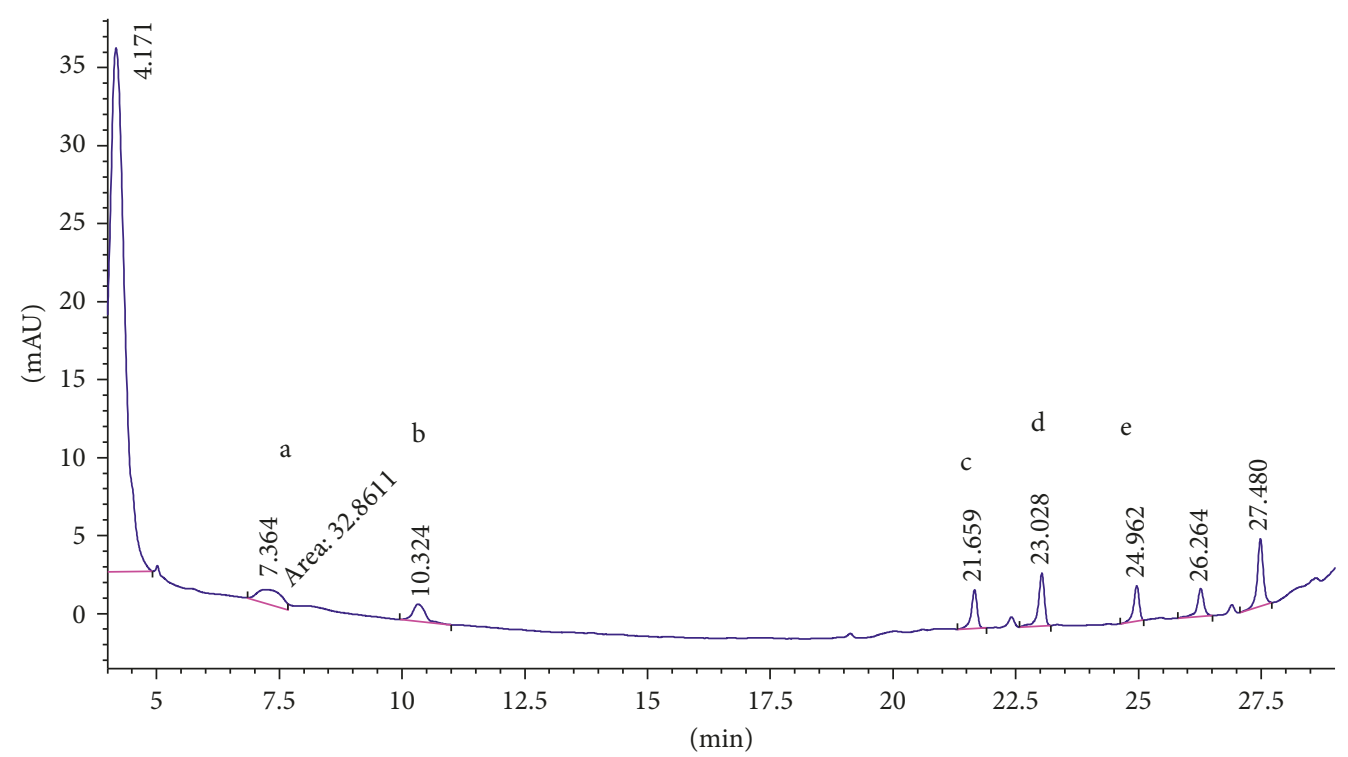

FIgURe 7: Chromatogram of extracted sample spiked (15 ppb) in 3\% acetic acid with LLE. Peak identified as a: 2,6-TDA, b: 2,4-TDA, c: 4,4'-MDA, d: $2,4^{\prime}-\mathrm{MDA}$, and e: $2,2^{\prime}$-MDA.

\section{Abbreviations}

DLLME: Dispersive liquid-liquid microextraction

HPLC-UV: HPLC-ultraviolet detector

LLE: $\quad$ Liquid-liquid extraction

MDA: $\quad$ Methylenedianiline

MDI: $\quad$ Methylene diphenyl isocyanate

PAAs: $\quad$ Primary aromatic amines

PU: $\quad$ Polyurethane

SPE: $\quad$ Solid-phase extraction

TDA: Toluenediamine

TDI: $\quad$ Toluene diisocyanate.

\section{Conflicts of Interest}

The authors declare that they have no conflicts of interest.

\section{Acknowledgments}

The authors thank the scientific experts of the Food and Drug Laboratories Research Center (FDLRC) for their kind cooperation during the study, and special thanks are due to the Henkel Corporation for their professional and skillful technical assistance.

\section{References}

[1] M. Mattarozzi, F. Lambertini, M. Suman, and M. Careri, "Liquid chromatography-full scan-high resolution mass spectrometry-based method towards the comprehensive analysis of migration of primary aromatic amines from food packaging," Journal of Chromatography A, vol. 1320, pp. 96102, 2013.

[2] C. J. Sennbro, C. H. Lindh, H. Tinnerberg et al., "Development, validation and characterization of an analytical method for the quantification of hydrolysable urinary metabolites and plasma protein adducts of 2,4- and 2,6-toluene diisocyanate, 1,5-naphthalene diisocyanate and 4,4'-methylenediphenyl diisocyanate," Biomarkers, vol. 8, no. 3-4, pp. 204-217, 2003.

[3] X. Trier, B. Okholm, A. Foverskov, M. L. Binderup, and J. H. Petersen, "Primary aromatic amines (PAAs) in black nylon and other food-contact materials," Food Additives and Contaminants, vol. 27, no. 90, pp. 1325-1335, 2010.

[4] O. Yavuz, S. Valzacchi, E. Hoekstra, and C. Simoneau, "Determination of primary aromatic amines in cold water extract of coloured paper napkin samples by liquid chromatography-tandem mass Spectrometry," Food Additives and Contaminants, vol. 33, no. 6, pp. 1072-1079, 2016.

[5] T. S. Oostdyk, R. L. Grob, J. L. Snyder, and M. E. McNally, "Solid-phase extraction of primary aromatic amines from aqueous samples; comparison with liquid-liquid extraction techniques," Journal of Environmental Science and Health, vol. 29, no. 8, pp. 1607-1628, 1994.

[6] L. Xu, C. Basheer, and H. K. Lee, "Review chemical reactions in liquid-phase microextraction," Journal of Chromatography A, vol. 1216, no. 4, pp. 701-707, 2009.

[7] H. Deng, F. Yang, Z. Li et al., "Rapid determination of 9 aromatic amines in mainstream cigarette smoke by modified dispersive liquid-liquid microextraction and ultra-performance convergence chromatography tandem mass spectrometry," Journal of Chromatography A, vol. 1507, pp. 37-44, 2017.

[8] X. Wang, L. Fu, G. Wei et al., "Determination of four aromatic amines in water samples using dispersive liquid-liquid microextraction combined with HPLC," Journal of Separation Science, vol. 31, no. 16-17, pp. 2932-2938, 2008.

[9] Q. Zhou, L. Pang, G. Xie et al., "Dispersive liquid phase microextraction of aromatic amines in environmental water samples," International Journal of Environmental Analytical Chemistry, vol. 90, no. 14, pp. 1099-1107, 2010.

[10] T. Zimmermann, W. J. Ensinger, and T. C. Schmidt, "In situ derivatization/solid-phase micro extraction: determination of polar aromatic amines," Analytical Chemistry, vol. 76, no. 4, pp. 1028-1038, 2004.

[11] T. C. Schmidt, M. Leß, R. Haas, E. V. Löw, and K. Steinbach, "Determination of aromatic amines in ground and waste water by two new derivatization methods," International Journal of Environmental Analytical Chemistry, vol. 74, no. 1, pp. 25-41, 2011. 
[12] R. C. Snyder and C. V. Breder, "High performance liquid chromatographic determination of 2,4 and 2,6-toluenediamine in aqueous extracts," Journal of Chromatography, vol. 236, no. 2, pp. 429-440, 1982.

[13] P. Carbonnelle, S. Boukortt, D. Lison, and J. P. Buchet, "Determination of toluenediamines in urine of workers occupationally exposed to isocyanates by high-performance liquid chromatography," Analyst, vol. 121, no. 5, pp. 663-669, 1996.

[14] C. Brede, I. Skjevrak, and H. Herikstad, "Determination of primary aromatic amines in water food simulant using solidphase analytical derivatization followed by gas chromatography coupled with mass spectrometry," Journal of Chromatography $A$, vol. 983, no. 1-2, pp. 35-42, 2003.

[15] C. Molins-Legua and P. Campins-Falco, "Solid phase extraction of amines," Analytica Chimica Acta, vol. 546, no. 2, pp. 206-220, 2005.

[16] M. Aznar, E. Canellas, and C. Nerín, "Quantitative determination of 22 primary aromatic amines by cation-exchange solid-phase extraction and liquid chromatography-mass spectrometry," Journal of Chromatography A, vol. 1216, no. 27, pp. 5176-5181, 2009.

[17] G. Kollbach, Smart Cure Technology from Henkel Achieves Cure and Regulatory Compliance in 3 Days, Flexible Packaging Adhesives, Henkel Corporation, Düsseldorf, Germany, 2009.

[18] G. M. Cramer and R. A. Ford, "Estimation of toxic hazard," Food and Cosmetics Toxicology, vol. 16, no. 3, pp. 255-276, 1987. 

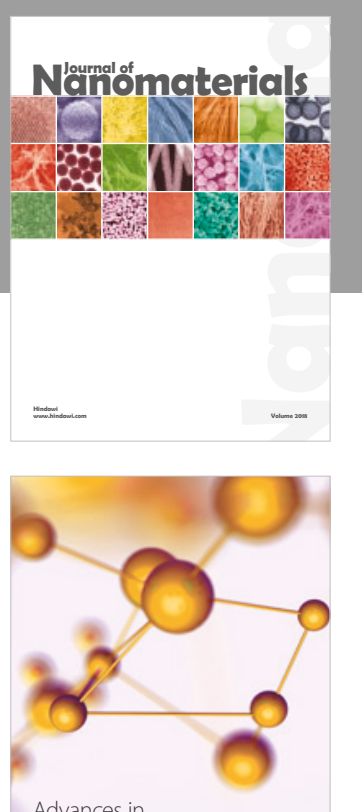

Physical Chemistry
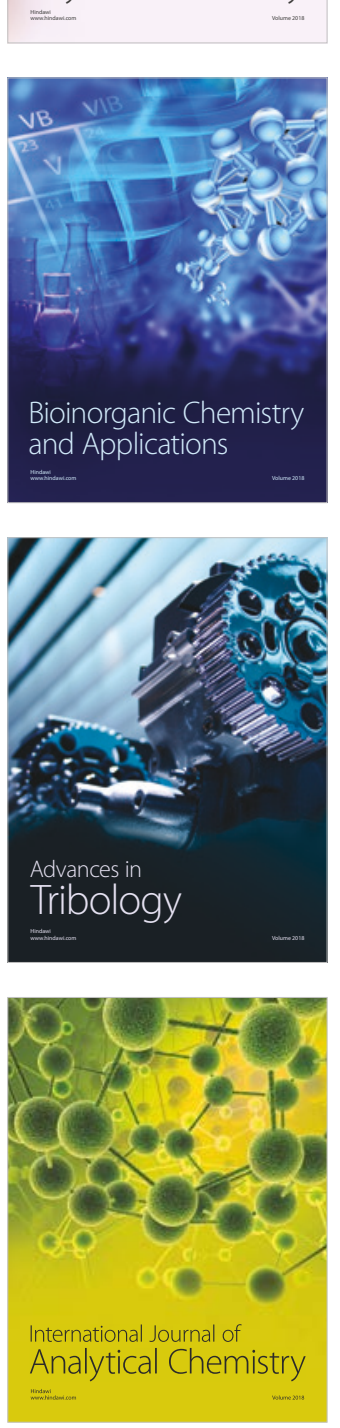

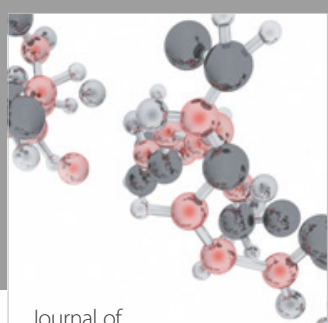

Analytical Methods

in Chemistry

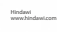

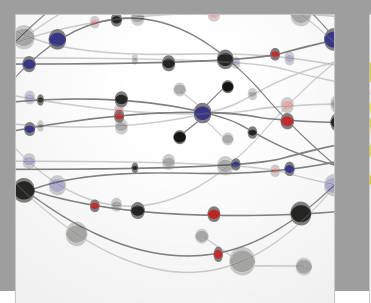

The Scientific World Journal

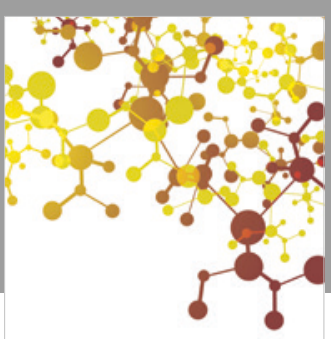

Journal of

Applied Chemistry
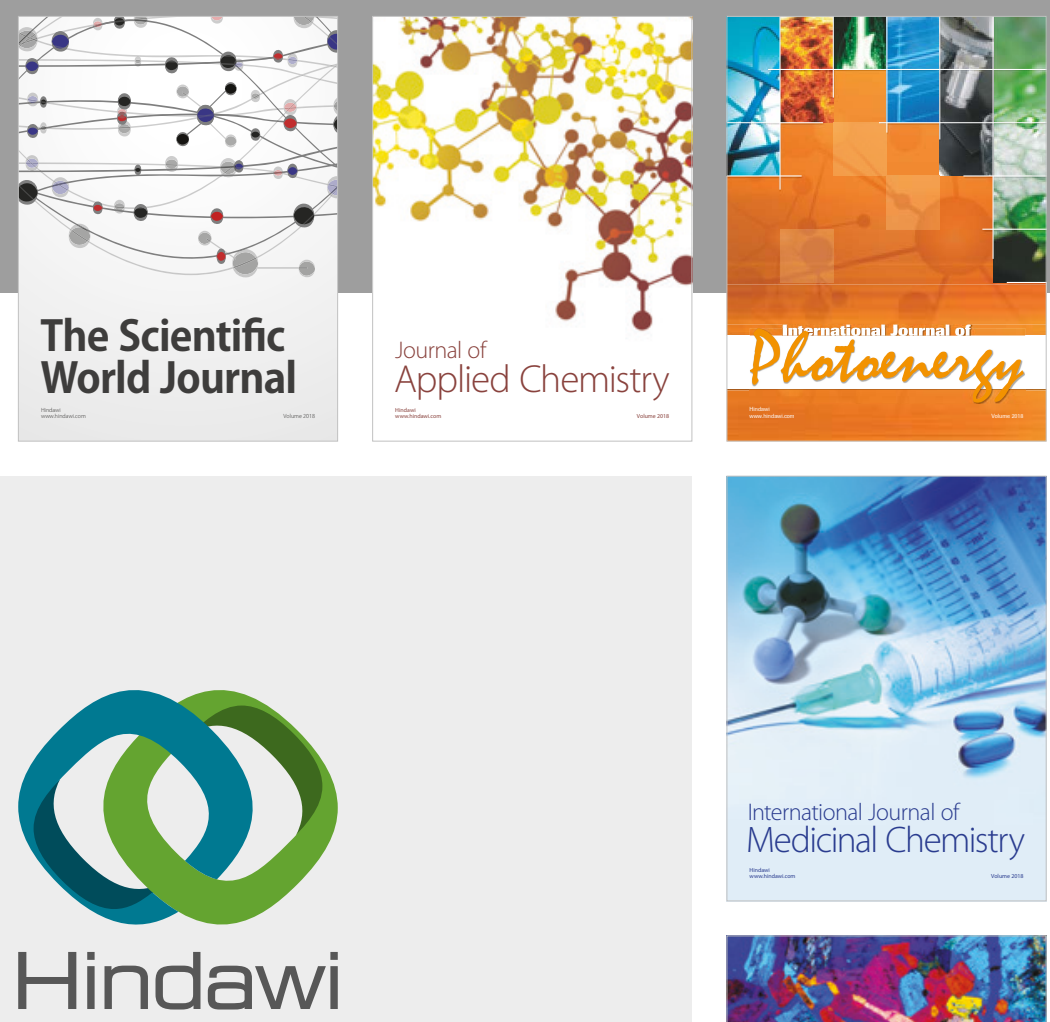

Submit your manuscripts at

www.hindawi.com
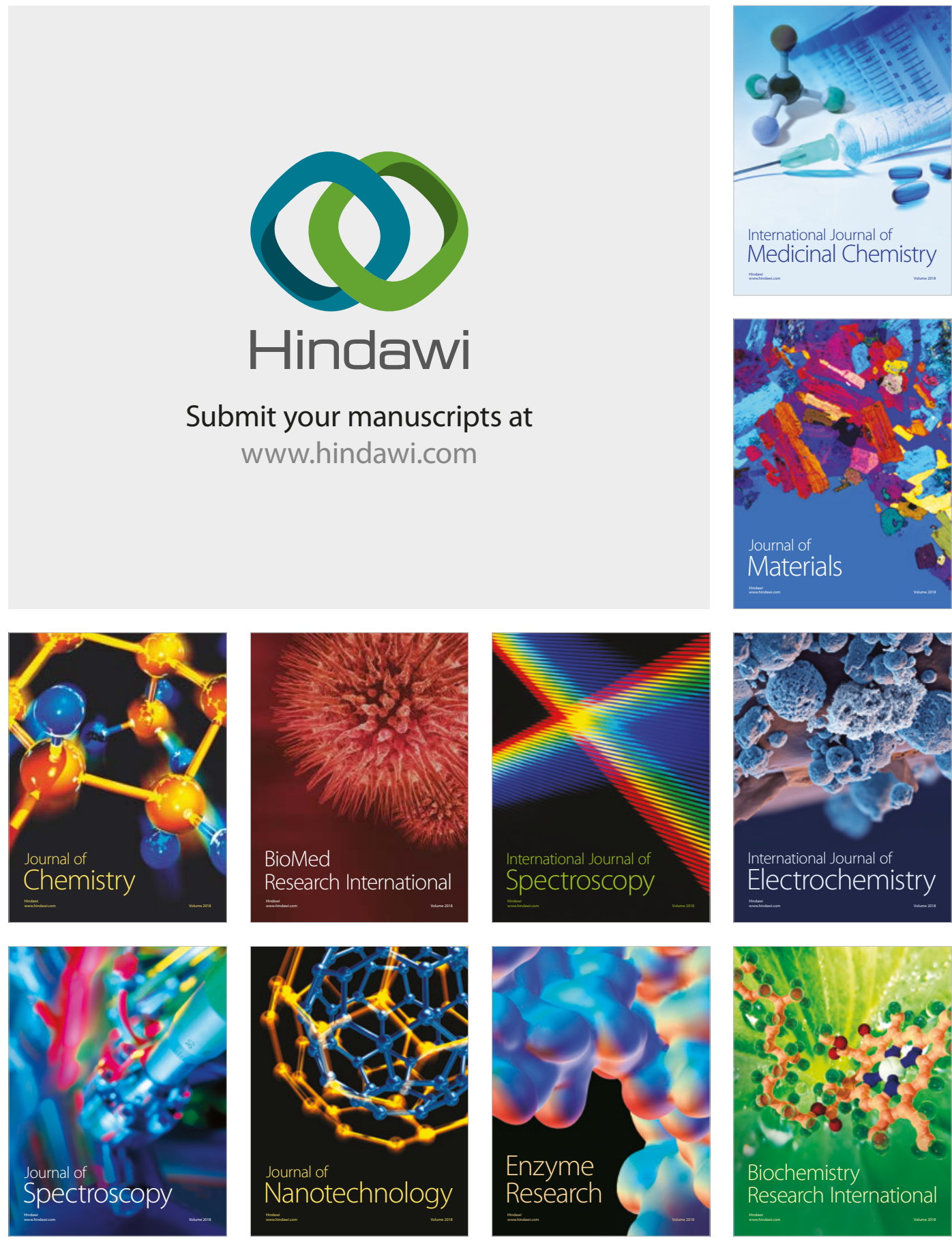
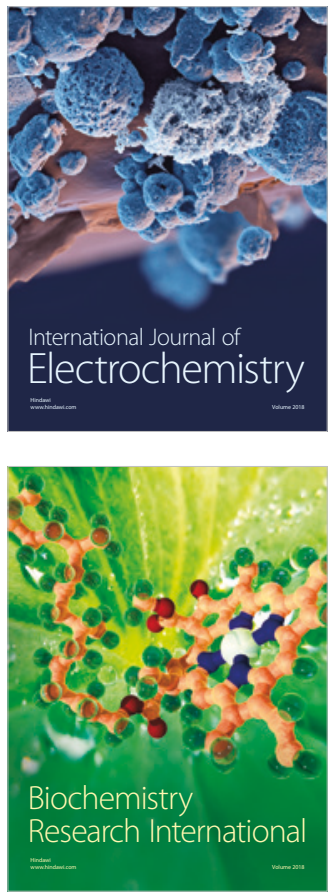